\title{
Water Diversion Capacity of Shallow Land Waste Repository Covered by Capillary Barrier of Soil
}

\author{
Toshihiro Morii', Kazunobu Matsumoto², Kaoru Kobayashi ${ }^{3}$ \\ ${ }^{1}$ Faculty of Agriculture, Niigata University \\ Niigata, Niigata 950-2181, Japan \\ morii@agr.niigata-u.ac.jp \\ ${ }^{2}$ Research Institute of Technology, Tobishima Corporation \\ Noda, Chiba 270-0222, Japan \\ Kazunobu_Matsumoto@tobishima.co.jp \\ ${ }^{3}$ College of Engineering, Ibaraki University \\ Hitachi, Ibaraki 316-8511, Japan \\ kaoru.kobayashi.kk@vc.ibaraki.ac.jp
}

\begin{abstract}
Capillary barrier (CB) is a tilting soil layer system which is composed of a finer soil layer underlain by a coarser soil layer. Water infiltrating into soil is suspended just above an interface between the soil layers and diverted downward along the interface. Because of this diversion of infiltration water, the CB has been employed in a top cover of waste landfills and mining wastes to reduce water infiltration into the protected waste materials. Water flow downward along the interface accumulates gradually its mass of flow due to continuous infiltration from the soil surface, and, at some length along the interface, water percolates into the coarser soil layer. A horizontal distance from the beginning of water flow to this point of percolation is called a diversion length of the CB, and is one of important parameters in designing structural dimensions and configuration of the CB system and in selecting a suitable combination of the finer and coarser soils. Shallow land waste repository, in which the top CB and bottom CB are placed to reduce infiltration due to rainfall and to divert percolating water through the protected waste material respectively, is proposed to isolate effectively a hazardous waste material or a very low level radioactive waste. A laboratory soil box test was conducted to investigate and estimate the diversion length, and a trial embankment was constructed in the field to investigate performance of the CB in the shallow land waste repository. The diversion length can be estimated with a practical accuracy based on saturated and unsaturated hydraulic properties of soils employed in the $\mathrm{CB}$, inclination of the interface and infiltration rate expected in the field. Field observation of soil water movement in the test embankment shows excellent and stable diversion of infiltration water in the CB system.
\end{abstract}

Keywords: Capillary Barrier of Soil, Shallow Land Waste Repository, Diversion Length, Test Construction

\section{Introduction}

Capillary barrier (CB) is a sloping soil layer system which is composed of a finer soil (usually sand) layer underlain by a coarser soil (usually gravel) layer. Water which infiltrates into the soil is suspended just above an interface between the soil layers and diverted along the interface, with the result that a vertical movement of water into deeper soil layers below the interface stops within some length along the interface. Because of this diversion of infiltration water, CB have been employed in a top cover of waste landfills and mining wastes to reduce water infiltration into the protected waste materials ([1], [2]). The CB has also been proposed to be used as a soil cover for slope stabilization against rainfall-induced slope failure ([3], [4]). Water flow downward along the interface between finer and coarser soil layers accumulates gradually due to continuous infiltration from the soil surface, and, at some length along the interface, water percolates into the coarser soil layer as shown in Figure 1 ([5], [6]). The horizontal length or distance from the beginning of water flow to this percolation into the coarser soil layer (breakthrough) is called a diversion length of the $\mathrm{CB}$, and is one of the important parameters in designing the CB system and selecting a suitable combination of the finer and coarser soils. It is well known that the diversion length can be estimated based on the infiltration flux, saturated and unsaturated hydraulic properties of the finer and coarser soils, and the slope of the interface [7]. Although Ross [5] discussed that the diversion length might 
be theoretically as much as $50 \mathrm{~m}$ in a dryer climate with an order of magnitude less infiltration, only 1 to 2 meters of the diversion length has been observed and published [6].

In this paper, a shallow land waste repository shown in Figure 2, in which a top CB and a bottom CB are placed to reduce infiltration due to rainfall and to drain percolating water through the protected waste material respectively, is proposed to isolate effectively a hazardous waste material or a very low level radioactive waste. As the shallow land waste repository is constructed on the ground surface, there may be no risk that groundwater enters the waste and diffuses pollutants into the surrounding environment. It should also be emphasized that the CB can maintain its function of water diversion for a long duration because it consists of natural materials such as sand and gravel. In the following section, the diversion length of $\mathrm{CB}$ which can be applied to a shallow land waste repository is determined based on a laboratory soil box test. Then trial construction shows some feasible proposition for construction of the shallow land waste repository. Observations of soil water movement in a test shallow land waste repository are also discussed to show the effectiveness of the CB.

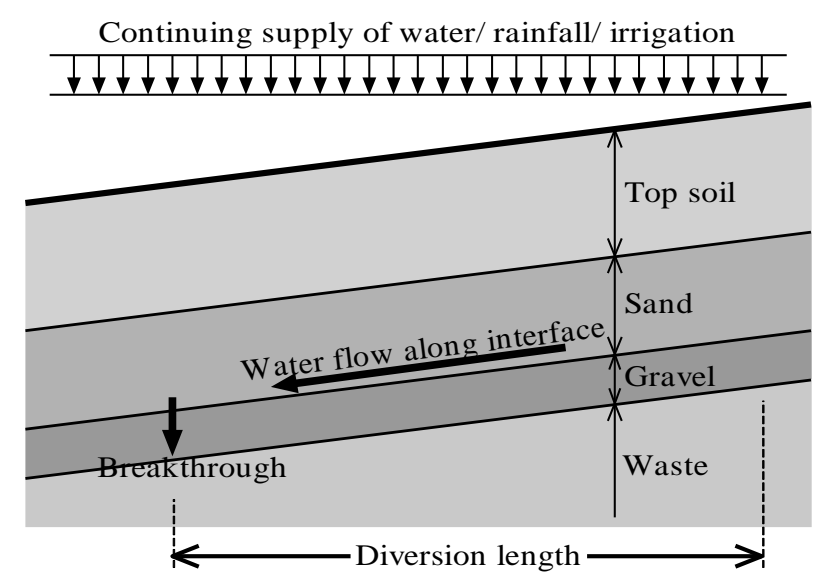

Fig. 1: Schematic layout of a capillary barrier of soil and diversion length.

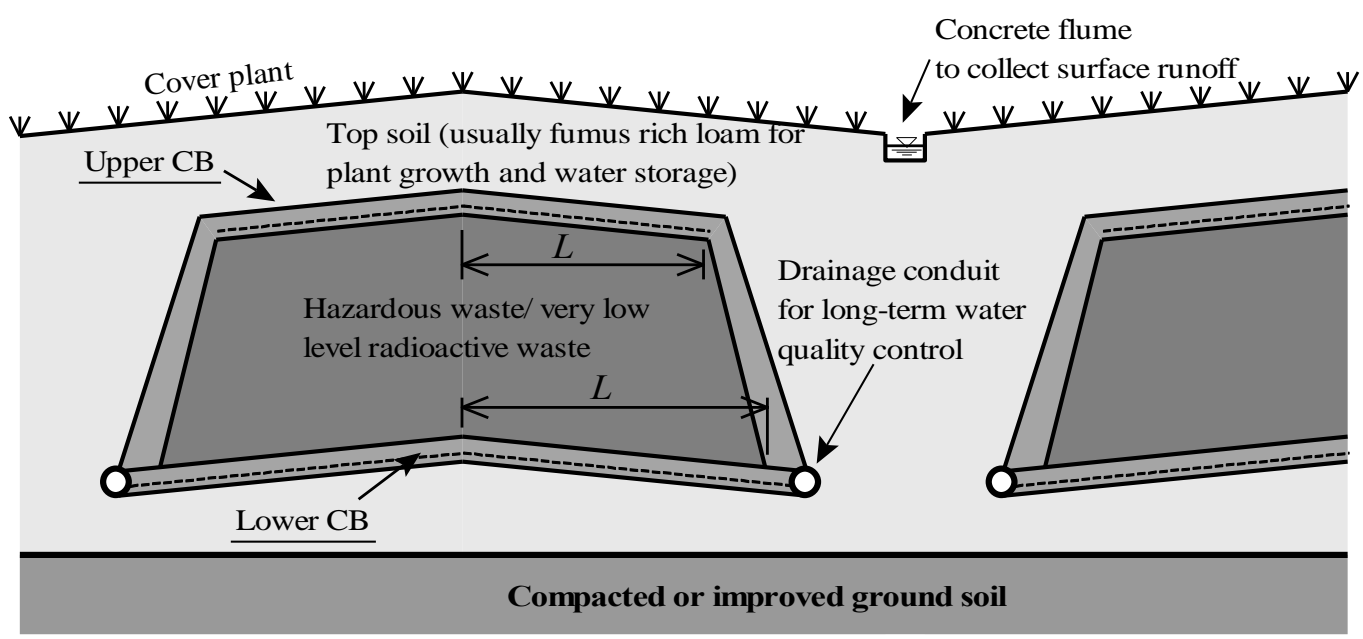

Fig. 2: Proposal of shallow land waste repository covered with upper CB and placed with bottom CB.

\section{Estimation of Diversion Length by Laboratory Soil Box Test}

\subsection{Soil Box Test}

In order to observe the breakthrough of water flowing along the interface, and to determine the diversion length, a series of laboratory soil box tests were carried out. Figure 3a shows an acrylic soil box, $300 \mathrm{~cm}$ in length, $20 \mathrm{~cm}$ in width and $50 \mathrm{~cm}$ in height, built in a steel frame. The soil box was placed horizontally, and the gravel was compacted $7.5 \mathrm{~cm}$ thickness, then the sand into $20 \mathrm{~cm}$ thickness as shown in Figure 3b. A completely-permeable polypropylene net was 
placed over the compacted gravel layer so that the sand particles did not fall into voids formed in the gravel layer. After a gauze sheet was spread over the soil surface to protect soil erosion due to rainfall droplets, one side of the soil box was jacked up to obtain the tilting interface of the CB. Infiltration water was supplied on the surface of the upper sand layer through emitting needles (syringe needles), $0.3 \mathrm{~mm}$ inner diameter, attached to the base plate of the water reservoir. To keep the acrylic front panel clean, the emitting needles were placed so that the rainfall droplets did not fall along the front panel. The intensity of rainfall was varied by adjusting the head of constant water in the water reservoir. Uniformity of the rainfall intensity over the soil surface was examined by measuring the water mass collected into a glass beaker during 10 minutes.

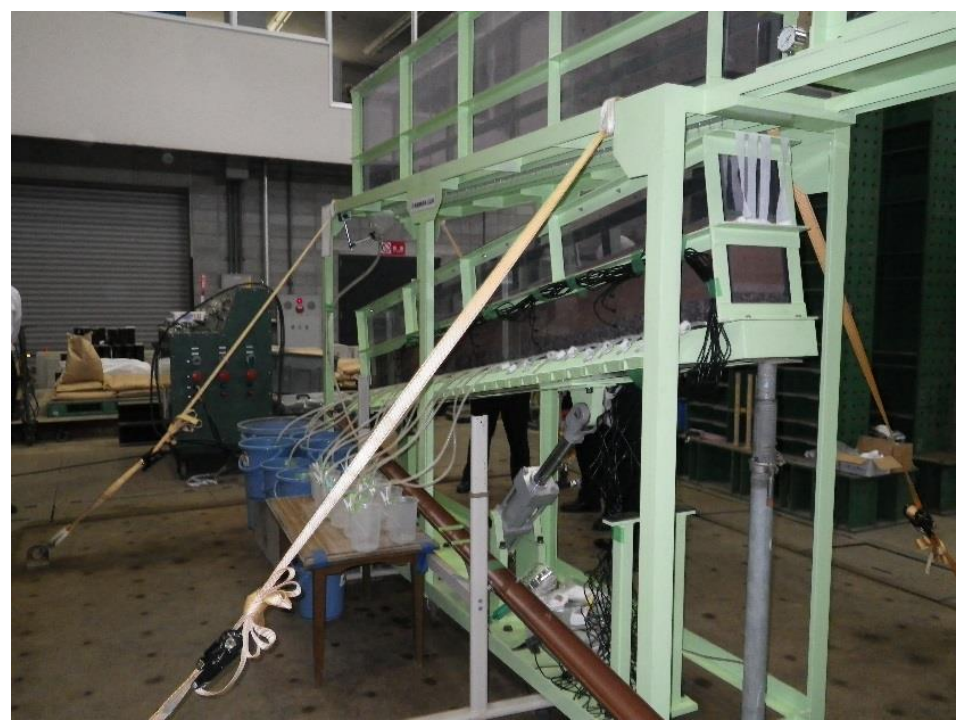

a. Soil box (lower set) and water reservoir (upper set)

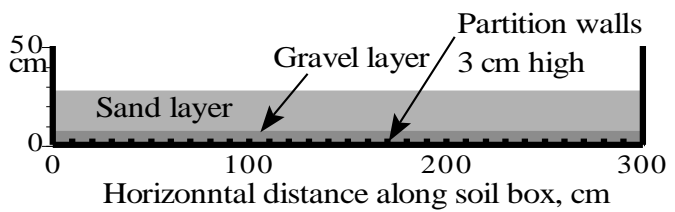

b. Partition walls attached to the bottom of the soil box.

Fig. 3: Test equipment prepared for the soil box test to measure diversion length of the CB.

Figure 4 shows the grain size distribution curves of sand and gravel used in the soil box test. The sand has less-5\% fine and coarse fractions; the gravel, commercially available, is siliceous with a mean particle size of 5 to $6 \mathrm{~mm}$. Relationships of negative pore pressure, $h$, with volumetric moisture content of sand and gravel are shown in Figure 5. The sand or gravel compacted into a cylindrical acrylic column $0.1 \mathrm{~m}$ in diameter and $1 \mathrm{~m}$ in height was immersed in the water, and, after one

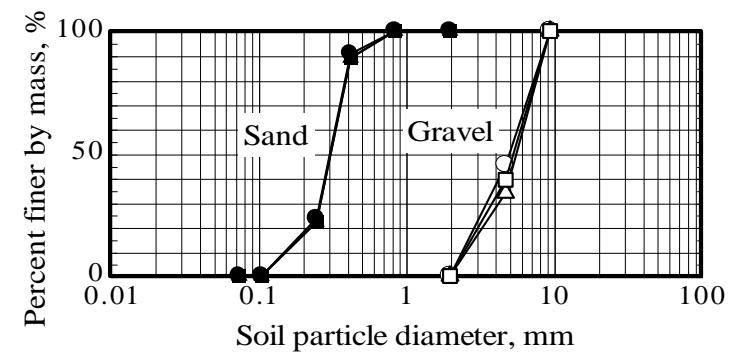

Fig. 4: Grain size distribution of sand and gravel used in the soil box test. 
week, the water content profile along the height of the soil column was measured and each measurement was associated with the negative of the sample elevation above the water table. In drying case, the soil column was fully saturated and then immersed in the water. Soil-water characteristic curves given in Figure 5 are determined by using the van Genuchten equation [8].

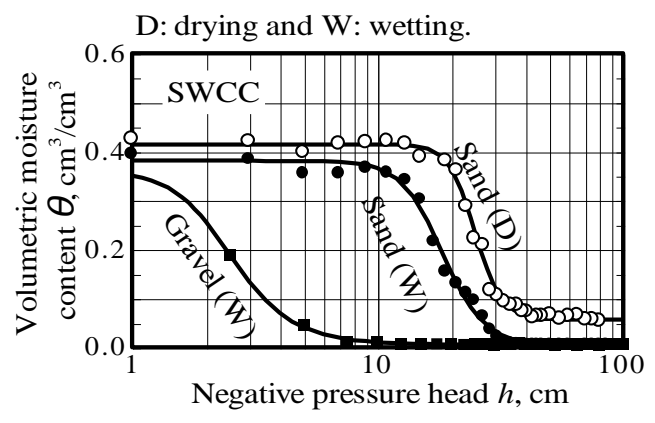

Fig. 5: Soil-water characteristic curves (SWCC) of sand and gravel measured by laboratory soil column tests.

\subsection{Measurement of Diversion Length}

12 runs were conducted by combining two interface angles, 5 and 10 degrees, with three infiltration rate $(5,10$ and 20 $\mathrm{mm} / \mathrm{h}$ ) in two soil boxes. The sand layer in one of two soil boxes was compacted into $90 \%$ of a maximum dry density, $1.62 \mathrm{Mg} / \mathrm{m} 3$, and $85 \%$ in the other soil box. Water which percolated into the lower gravel layer was collected along partition walls $3 \mathrm{~cm}$ high attached transversely $10 \mathrm{~cm}$ intervals on the bottom plate of the soil box as shown in Figure $3 \mathrm{~b}$, and led to a collecting beaker through a silicon tube connected to the lowest position of the side wall of the soil box as shown in Figure 3a. The diversion length was determined by measuring the volume of water collected into the collecting beaker along the bottom of the soil box. Figure 6 shows a typical measurement of the water volume collected along the distance of the bottom of the soil box (case of $90 \%$ compaction of the sand layer, 10 degrees in slope and $10 \mathrm{~mm} / \mathrm{h}$ of infiltration rate). The total amount of the water volume, $1077.4 \mathrm{~cm} 3 / 10 \mathrm{~min}$., was converted into $10.8 \mathrm{~mm} / \mathrm{h}$ of the infiltration rate, and it was confirmed that a mass balance between infiltration and drainage of water is kept. In this case, a diversion length of $170 \mathrm{~cm}$ was determined from Figure 6.

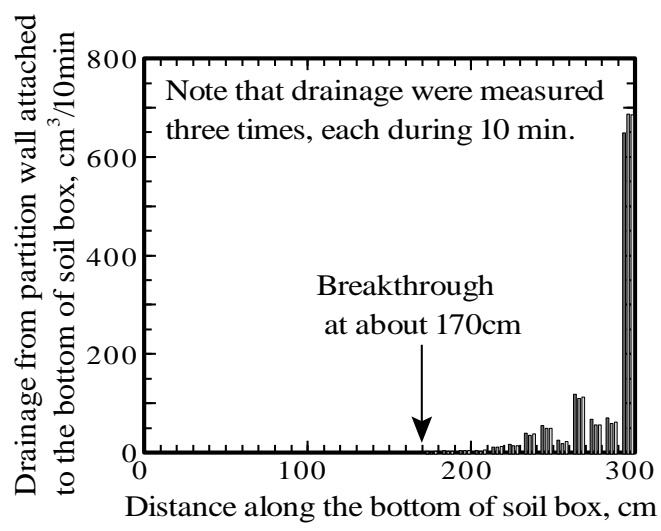

Fig. 6: Typical measurement of water volume collected along the bottom of the soil box.

\subsection{Estimation of Diversion Length}

Theoretical equations have been proposed to estimate the diversion length of the CB ([5], [7] and [9]. Among these, the equation by Steenhuis et al. [7] is effectively adaptable ([6], [10]). In the case where an infiltration rate, q, is much smaller than a saturated hydraulic conductivity of sand (the upper finer soil), Ks, the equation of the diversion length, L, is given by 


$$
L \leq \frac{K_{s}}{q} \tan \phi\left[\alpha^{-1}+\left(h_{a}-h_{w}\right)\right]
$$

in which $\varphi$ is a slope angle of interface, $h_{a}$ and $h_{w}$ are an air entry value of sand and a water entry value of gravel, respectively. $\alpha$ is an exponential constant describing the relationship between $h$ and unsaturated hydraulic conductivity, $K$, of sand near saturation:

$$
\begin{aligned}
& K=K_{s} \quad|h|<h_{a} ; \\
& K=K_{s} \exp \left[\alpha\left(h-h_{a}\right)\right] \quad|h| \geq h_{a}
\end{aligned}
$$

The diversion lengths measured in the soil box test are given in Figure 7 and compared with the estimations calculated by Equations $1,2 . K_{s}$ of $90 \%$-compacted sand is $1.31 \times 10^{-4} \mathrm{~m} / \mathrm{s}$, and $85 \%$-compacted sand $1.91 \times 10^{-4} \mathrm{~m} / \mathrm{s}$. The unsaturated hydraulic properties of the sand, $h_{a}, h_{w}$ and $\alpha$, are determined to be $13 \mathrm{~cm}, 1 \mathrm{~cm}$ and $0.12 / \mathrm{cm}$, respectively, based on Figure 5 and Nakafusa et al. [11]. Experimental data published by Walter et al. [6] and the observed data by Morii et al. [12] are also plotted in Figure 7. The value of the data denoted by a small arrow will be larger because the measurement was restricted to the length of the soil box, $300 \mathrm{~cm}$. Figure 7 shows that Equations 1, 2 proposed by Steenhuis et al. [7] can be practically to estimate the diversion length of the CB. Based on the results in Figure 7, about four meters of diversion length can be practically achieved in the CB for the shallow land waste repository.

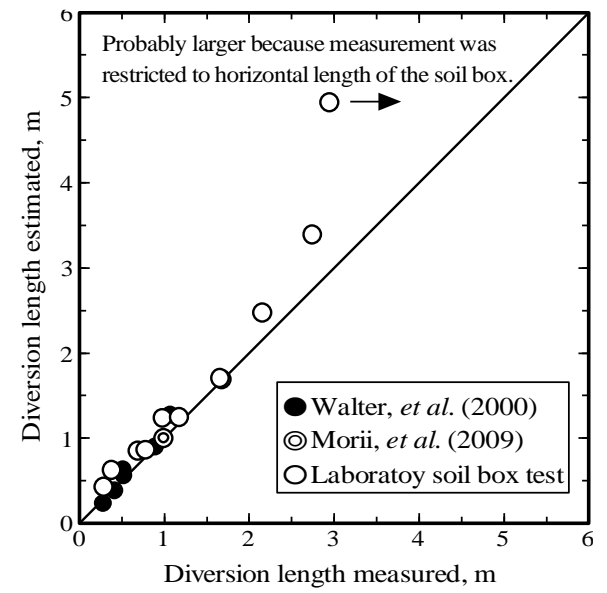

Fig. 7: Comparison of the diversion length between measurements and estimations.

\section{Soil Water Movement in Test Shallow Land Waste Repository in the Field}

\subsection{Construction of Test Shallow Land Waste Repository}

A test shallow land waste repository was constructed in order to monitor soil water movement in the field and to examine water diversion by the CB. The upper CB was not included because it was planned only to observe the diversion of infiltration water. The original ground soil was compacted with a surface inclination of 5 degrees. The gravel was placed over the compacted ground surface and compacted by using the plate-type bucket in $10 \mathrm{~cm}$ thickness and in $4 \mathrm{~m}$ horizontal lengths (Figures 8a and b), then the sand was placed over it in $15 \mathrm{~cm}$ thickness. After constructing the CB layer, sandy soil, polypropylene soil-bags which simulated containers for waste storage, and sandy soil were placed and compacted successively higher (Figure 8c, and also see Figure 10 in Section 3.2). Uniformity in density of the compacted sand layer is an important property which guarantees the water diversion in the CB system because the diversion length directly relates to the saturated hydraulic conductivity of sand as shown in Equation 1. After constructing the CB layer, 19 cylindrical sand cores, $100 \mathrm{~cm}^{3}$ in volume and $5 \mathrm{~cm}$ in height, were sampled, and the densities of the sand cores were measured in laboratory. Figure 9a shows the mean value and standard deviation of the dry density, $\rho_{d}$, of sand cores on a normal distribution curve, together with the saturated hydraulic conductivity of sand measured by laboratory permeability test in 
Figure $9 \mathrm{~b}$. Figure 9 shows that the saturated hydraulic conductivity corresponding to a maximum density expected with 95\%-confidence is about $65 \%$ lower than that corresponding to a minimum density along an average line between $K_{s}$ and $\rho_{d}$ in Figure $9 \mathrm{~b}$, with the result that the diversion length may vary.

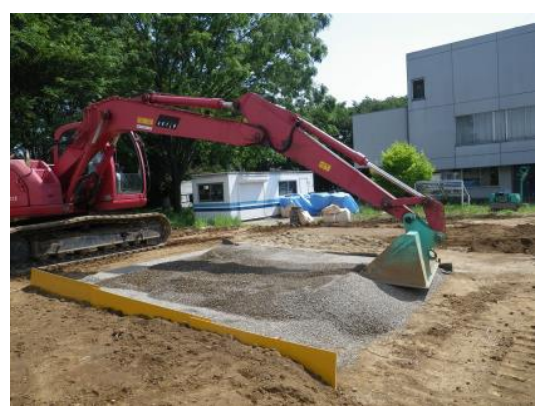

a. Gravel layer compacted by the platetype bucket.

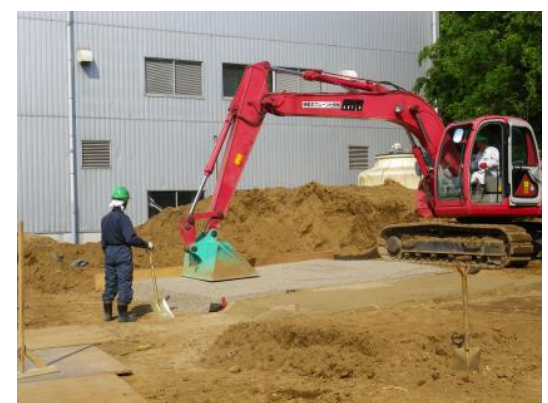

b. Sand layer compacted by the platetype bucket.

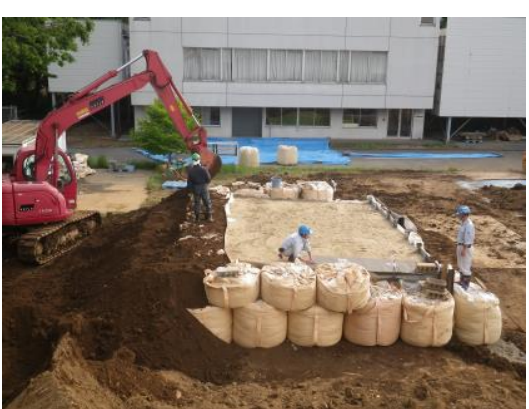

c. Test shallow land waste repository constructed.

Fig. 8: Construction of test shallow land waste repository.

(a) Normal distribution of dry density measured in the compacted sand layer

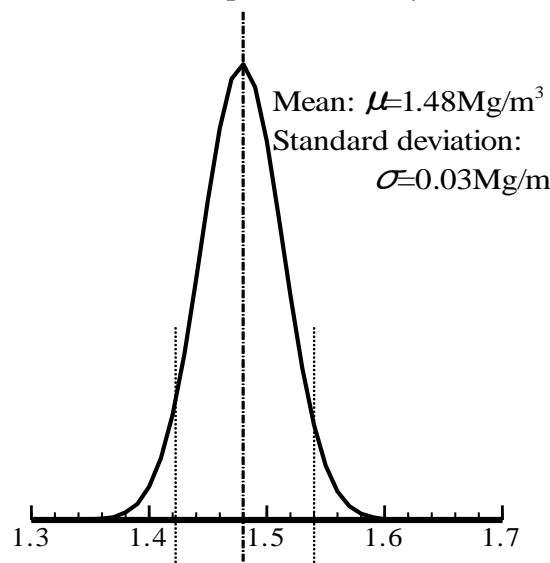

Dry density of sand $a_{l}, \mathrm{Mg} / \mathrm{m}^{3}$

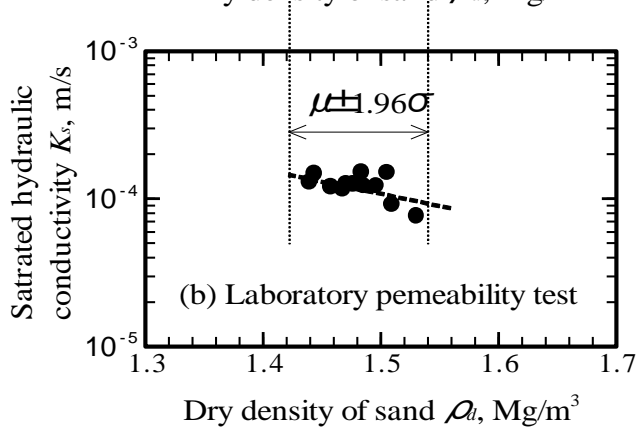

Fig. 9: Frequency distribution of dry density measured in the compacted sand layer and the saturated hydraulic conductivity measured in laboratory.

\subsection{Soil Water Movement}

The volumetric moisture contents measured in the test shallow land waste repository from June to September are shown in Figure 11 together with the structural section in Figure 10. Two plots were prepared in the test construction, a CB layer plot and a reference plot without $\mathrm{CB}$ both $2 \mathrm{~m}$ in width. Figures 11(a) and 11(b) show the volumetric moisture contents (VMC) measured in the sand layer and gravel layer, respectively, in the CB layer plot. The VMCs in Figures 
11(c) and 11(d) were measured in the sand of the reference plot at the same level as Figure 11a and 11b respectively. Rainfall intensity measured 5-minute intervals is given by an inverse bar with the right vertical axis of each figure. Comparing d with $\mathrm{b}$ and $\mathrm{c}$ in Figure 11, it is found that the soil water which infiltrates from the top surface of the test repository enters into the sand layer but does not enter into the gravel layer underling the sand layer. This is exactly due to the water diversion by the $\mathrm{CB}$.

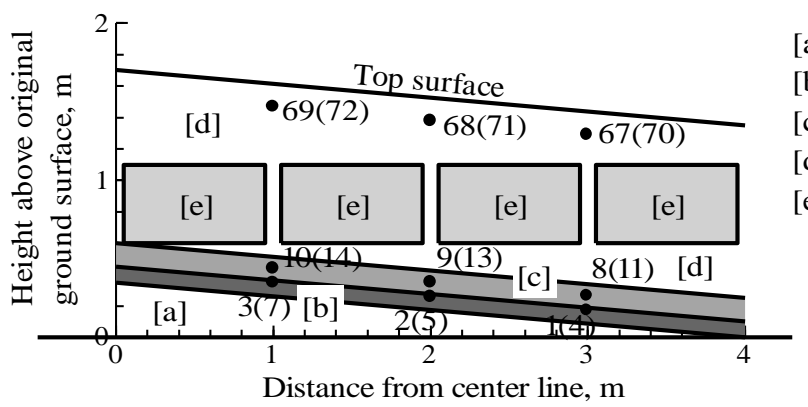

[a]: Loamy soil with surface inclination of 5 degrees

[b]: Gravel constituing CB layer, $10 \mathrm{~cm}$ thickness

[c]: Sand constituting CB layer, $15 \mathrm{~cm}$ thickness

[d]: Sandy soil

[e]: Sandy soil packed in polypropylene soilbag

- : Soil moisture sensor EC-5, in which

a numeral and a numeral in parentheses

represent sensor number embeded in test

plot with $\mathrm{CB}$ and without $\mathrm{CB}$, respectively.

Fig. 10: Structural section of the test shallow land waste repository.
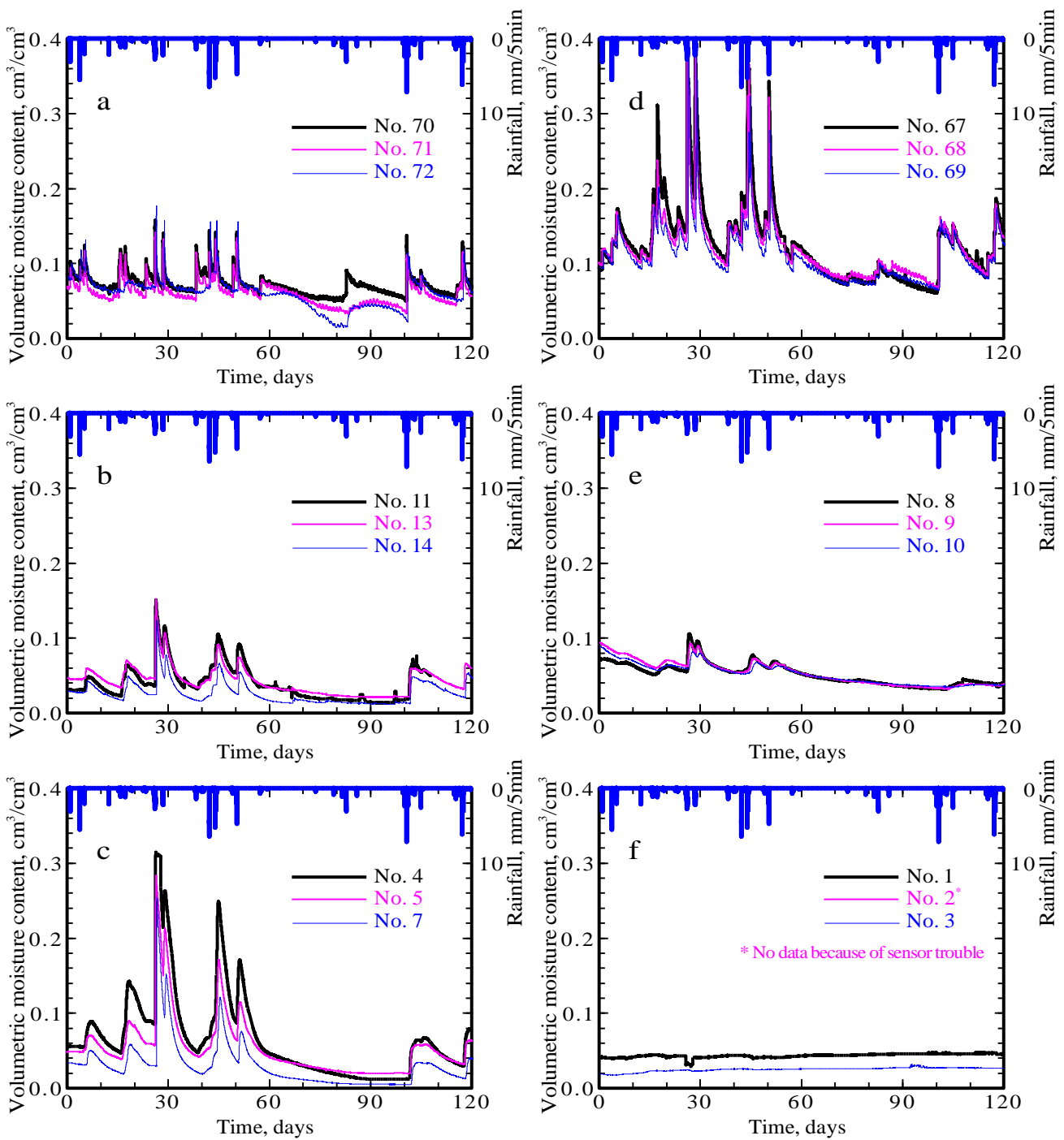

Fig. 11: Volumetric moisture content measured in the test shallow land waste repository. 


\section{Conclusion}

A shallow land waste repository, in which an upper CB and bottom CB are placed to reduce infiltration due to rainfall and to drain percolating water through the protected waste material respectively, was proposed to isolate effectively a hazardous waste material or a very low level radioactive waste. The laboratory soil box test and the test shallow land waste repository constructed in the field reveal that:

1. The diversion length which determines the structural dimensions of the shallow land waste repository can be estimated based on the hydraulic properties of sand and gravel employed in the $\mathrm{CB}$, the inclination of the CB interface and the infiltration rate expected in the field. Equations 1 and 2 proposed by Steenhuis et al. (1991) is recommended to estimate the diversion length of the CB.

2. The test shallow land waste repository showed the excellent and stable diversion of infiltration water provided by the CB. A continuing observation of soil water movement may be required to evaluate the CB performance for a long duration.

\section{Acknowledgements}

The present study was supported by the Grant-in-Aids for Scientific Research (A), No. 25252043, made by the Ministry of Education, Science, Sports and Culture of Japan, and by the Grant for Environmental Research Projects made by the Sumitomo Foundation, Japan. These are well acknowledged.

\section{References}

[1] J. C. Stormont and C. E. Anderson, "Capillary barrier effect from underlying coarser soil layer," Journal of Geotechnical and Geoenvironmental Engineering, vol. 125, no. 8, pp. 641-648, 1999.

[2] E. K. Yanful, P. H. Simms, R. K. Rowe and G. Stratfoed, "Monitoring an experimental soil waste cover near London, Ontario, Canada," Geotechnical and Geological Engineering, vol. 17, 1999.

[3] D. Tami, H. Rahardjo, E. C. Leong and D. G. Fredlund, "A physical model for sloping capillary barriers," Geotechnical Testing Journal, vol. 27, no. 2, pp. 173-183, 2004.

[4] H. Rahardjo, H. Krisdani and E. C. Leong, "Application of unsaturated soil mechanics in capillary barrier system," in Proceedings of the 3rd Asian Conference on Unsaturated Soils, Nanjing, China, 2007, pp. 127-137.

[5] B. Ross, "The diversion capacity of capillary barriers," Water Resources Research, vol. 26, no. 10, pp. 2625-2629, 1990.

[6] M. T. Walter, J. S. Kim, T. S. Steenhuis, J. Y. Parlange, A. Heilig, R. D. Braddock, J. S. Selker and J. Boll, "Funneled flow mechanisms in a sloping layered soil: Laboratory investigation," Water Resources Research, vol. 36, no. 4, pp.841-849, 2000.

[7] T. S. Steenhuis, J. Y. Parlange and K. J. Kung, "Comment on "The Diversion Capacity of Capillary Barriers" by Benjamin Ross," Water Resources Research, vol. 27, no. 8, pp. 2155-2156, 1991.

[8] D. B. Stephens, Vadose Zone Hydrology, Florida: CRC Press, 1996.

[9] K. J. S. Kung, "Preferential flow in a sandy vadose soil, 2, Mechanism and implications," Geoderma, vol. 46, pp. 59-71, 1990.

[10] J. K. Smesrud and J. S. Selker, "Effect of soil-particle size contrast on capillary barrier performance," Journal of Geotechnical and Geoenvironmental Engineering, vol. 127, no. 10, pp. 885-888, 2001.

[11] S. Nakafusa, K. Kobayashi, T. Morii and Y. Takeshita, "Estimation of water diversion provided by capillary barrier of soils," in Proceedings of the 5th Asia-Pacific Conference on Unsaturated Soils, Pataya, Thailand, 2012, vol. 2, pp. 773-777.

[12] T. Morii, Y. Takeshita, M. Inoue and S. Matsumoto, "Alternative measures for soil slope stability using capillary barrier of soil," in Proceedings of the 4th Asia-Pacific Conference on Unsaturated Soils, Newcastle, Australia, 2009, vol. 2, pp. 319-324. 